\title{
Diagnosis and Management of Blunt Trauma Abdomen
}

\author{
Authors \\ Dr Yogendra Singh Wadiwa ${ }^{1}$, Dr Ajay Gangii ${ }^{2}$, Dr Upendra Bhardwaj ${ }^{3}$, \\ Dr Lal Mani Singh ${ }^{4}$ \\ ${ }^{1}$ Assistant Professor Surgery NSCB Medical College Jabalpur MP, India \\ ${ }^{2}$ Professor Govt Medical College Khandawa, MP, India \\ ${ }^{3}$ RSO Surgery Gajra Raja Medical College Gwalior \\ ${ }^{4}$ Associate Professor Surgery SS Medical College, Rewa MP India
}

\section{Introduction}

Blunt injury as causes of intra-abdominal injuries have been recognized since historical times. Aristotle was the first to record visceral injuries from blunt trauma. Hippocrates and Galen are said to have given apt description of the condition. ${ }^{[1]}$ The development of emergency medical service is an important milestone in the history of clinical and surgical practice of trauma. Greeks required physicians to be present during the battle and Romans established the hospitals close to the battlefield. ${ }^{[1]}$ Advanced imaging techniques like spiral CT scan and MRI has made early detection of blunt abdominal injuries easier.

In view of increasing number of vehicles and consequently road traffic accidents, this dissertation has been chosen to study the cases of blunt abdominal trauma with reference to the patients presenting at health care centre and purpose of present study to know role of ultrasonography and x-ray abdomen standing in diagnosis of blunt trauma abdomen and to compare conservative management with operative management.

\section{Aims and Objectives}

1. To study role of ultrasonography; X-Ray abdomen Standing and CT scan in blunt trauma abdomen.

2. To study conservative vs oprative management.

\section{Material and Method}

Present prospective study conducted at department of surgery G R Medical College Gwalior from July 2011 to june2013, total 150 patients included in study that got admitted in department coming from casualty and OPD, after hospitalization patient resuscitated, proper history noted, specially noted mood of trauma RTA, fall or assault, and examined for site and severity of trauma. When patient get stable then proceeded for investigation according to needs to confirm diagnosis. once patients diagnosis confirmed then some patient treated conservative those doesn't needs surgery and those patient needs surgery shifted to OT and operated operative finding noted for data ie.name of organ injured grade of injury salvageable or not. In post operative period treated 
according to needs, after recovery patient discharged and called for fallow up in OPD.

\section{Result}

This is a prospective study of 150 cases of blunt abdominal trauma conducted in health care centre from July 2011 to June 2013. Males (83\%) outnumbered females (17\%). The most common age group affected is of 21-30 years which forms the young and reproductive group. Road traffic accident forms the most common mode of injury (56.2\%). Majority of our study population (90\%) presented with pain abdomen followed by abdominal distention (56\%). The latent period in our study was < 18 hours in $90 \%$ of cases. X ray erect abdomen and chest $\mathrm{X}$ ray forms important investigational tools. Ultra sonography (FAST) has picked up solid organ injury or collection in 90-95\% of cases. So it becomes an important tool in emergency set up, more so in hemodynamically unstable patients. The most common injured organ in the present study is spleen followed by liver, kidney, bowel and pancreas in the decreasing order. For splenic injury, most common surgery performed was Splenectomy in 21 patients followed by splenorraphy in 4 patients. Rest was all managed conservatively.

Table: 1 Age distribution

\begin{tabular}{|l|c|c|}
\hline Age group & Our study & Davis et al $^{25}$ \\
\hline $11-20$ & $4.1 \%$ & $19 \%$ \\
\hline $21-30$ & 45.8 & $24 \%$ \\
\hline $31-40$ & 29.2 & $15 \%$ \\
\hline $41-50$ & 8.3 & $13 \%$ \\
\hline $51-60$ & 8.3 & $6 \%$ \\
\hline $61-70$ & 2.1 & $3 \%$ \\
\hline $71-80$ & 2.1 & - \\
\hline
\end{tabular}

Table: 2 mode of injury

\begin{tabular}{|l|c|c|c|}
\hline Cause & Our study & Davis et al $^{\mathbf{2 5}}$ & Khanna et al $^{\mathbf{2 6}}$ \\
\hline Road Traffic accident & $56.2 \%$ & $70 \%$ & $57 \%$ \\
\hline Fall from height & $25 \%$ & $6 \%$ & $15 \%$ \\
\hline Assault / injury with blunt object & $18.8 \%$ & $17 \%$ & $33 \%$ \\
\hline
\end{tabular}

Table: 3 incidence of organ injury

\begin{tabular}{|l|c|c|c|c|c|}
\hline Organ injured & Our study & Cusheri $^{\mathbf{1}}$ & Davis et al $^{\mathbf{2 5}}$ & Cox et al $^{\mathbf{2 8}}$ & Khanna et al $^{\mathbf{2 6}}$ \\
\hline Spleen & $39.6 \%$ & $25 \%$ & $25 \%$ & $46 \%$ & $26 \%$ \\
\hline Liver & $37.5 \%$ & $15 \%$ & $16 \%$ & $33 \%$ & $37 \%$ \\
\hline Kidney & $12.5 \%$ & & & & \\
\hline Pancreas & $4.16 \%$ & & & & \\
\hline Mesentery & $4.1 \%$ & $5 \%$ & $4 \%$ & $10 \%$ & $47 \%$ \\
\hline Bladder & $2 \%$ & $6 \%$ & $4 \%$ & & \\
\hline
\end{tabular}

Table: 4 Organs involved in Polytrauma

\begin{tabular}{|l|c|c|}
\hline Organs injured & No of patients & Percentage \\
\hline Spleen + hollow viscus & 4 & $8.3 \%$ \\
\hline Spleen + renal & 2 & $4.2 \%$ \\
\hline Spleen + liver & 2 & $4.2 \%$ \\
\hline Renal + hollow viscus & 1 & $2.1 \%$ \\
\hline Spleen + Liver + renal & 1 & $2.1 \%$ \\
\hline Liver + pancreas & 2 & $4.2 \%$ \\
\hline Total & \multicolumn{2}{|c|}{$\mathbf{2 5 \%}$} \\
\hline
\end{tabular}




\section{Discussion}

In our study male to female ratio is $83.3: 30$, it is clear that males are more common victims of blunt trauma abdomen when compared to Davis et al study. ${ }^{[2]}$ The incidence is more in males as males are involved in road traffic accident (RTA) and Assaults.

Age group - in our study majority of our study population belonged to $21-30 \mathrm{yrs}$ of age followed by $31-40 y r s$ of age as young people are involved in RTA which is compared to Davis et al study ${ }^{[2]}$ as showed in table 1 .

In our study blunt trauma injury percent due to road traffic accident, fall from height and assault injury with blunt object is $56.2 \%, 25 \%$ and $18.8 \%$ which compared with Devis et al ${ }^{[2]} 70 \%, 6 \%$ and $17 \%$ and Khanna et $\mathrm{al}^{[3]} 57 \%, 15 \%$ and $33 \%$ as showed in table 2, it clearly states that RTA is the most common mode of injury because of increased number of vehicles recently. The young people also give priority to speed rather than safety.

In our series abdominal pain was the most common presenting complaint accounting $90 \%$. Abdominal distention was next most common presentation in $56 \%$ of cases. The signs and symptoms are misleading in case of blunt trauma abdomen and are masked by concomitant head injury, chest injury and alcohol consumption. Retroperitoneal organ injury was missed in DPL and USG abdomen. In Davis et al study ${ }^{[2]} 43 \%$ had no specific complaints. So this emphasizes the importance of careful and continuing observation and repeated clinical examination of individuals with blunt trauma abdomen.

Latent period is the interval between the time of injury to presentation to our hospital $.41 .7 \%$ of our patients presented between 7-12 hours after injury. $31 \%$ presented within 6 hrs after injury. This time lag is due to lack of facility for transport. Many belonged to rural area. Urine microscopy was done in all cases. There was hematuria either macro/micro in 24 cases. All the cases showed renal injury on CT scan. Plain erect $\mathrm{X}$ ray of abdomen was done in 135 cases. Gas under diaphragm was found in 15 cases. In Davis et al study abdominal X ray was abnormal in $21 \%$ cases. In our study it is abnormal in $23 \%$ of cases of blunt injury abdomen. USG abdomen (Focussed Abdominal Sonography for Trauma) was done in all cases out of which 135 cases had solid organ injury. Therefore USG abdomen is more reliable in detecting solid organ injury and free fluid in the abdomen. Imaging is essential in early decision making. Focussed Assessment with Sonography in Trauma (FAST) examination of pericardial, peri-hepatic, peri-splenic and pelvic areas help in early detection of clinically significant abdominal injury. FAST examination can be performed repeatedly and is an excellent adjuvant to physical examination compared with mohamaddi A et al study $2012^{[4]}, 2008^{[5]}$ and Lee BC et al study. ${ }^{[6]}$

In our study, spleen is the most common organ injured in blunt injury abdomen as compared to international series, accounting to $40 \%$, followed by liver in $37.5 \%$ cases and kidney in $12.5 \%$ cases as compared with Cusheri et $\mathrm{al}^{[1]}$, Davis et $\mathrm{al}^{[2]}$, Cox et $\mathrm{al}^{[7]}$, Khanna et $\mathrm{al}^{[3]}$ study as showed in table 3 .

In our study, most patient of blunt trauma abdomen was managed conservatively and closure of bowel which was associated with solid organ injury was done in 15 cases. Splenectomy was done in 21 cases because of hemodynamic instability and severity of injury. Splenorraphy was done in 6 cases and most of liver injuries were managed conservatively. Hepatorraphy was done in 15 cases. All renal injury cases were managed conservatively. Drainage procedure was done in 4 patients of pancreatic injury. Our study compared with Raza $M$ et al $2013^{[8]}$, Giannopoulos GA et al $2009^{[9]}$, Malhotra AK et al $2002^{[10]}$ study.

Total 23 patients died in our study. 12 patients belonged to operative group. They died in post operative period, majority of them died due to septicaemia, 11 patients died during resuscitation. Therefore mortality in the present study is $14.6 \%$ which is compared with the other published 
studies in our country (Khanna et $\mathrm{al}^{[3]}$ ). The mortality rate in Di Vincenti et al ${ }^{[11]}$ study was $23 \%$. Cox et $\mathrm{al}^{[7]}$ study reports mortality of $10 \%$ and in Davis et al ${ }^{[2]}$ study it was $13.3 \%$.

\section{Conclusion}

Blunt injury abdomen with solid organ injury forms considerable load of patients in our society. Most common age group involved is 21-30 years. Predominantly males are affected in large proportions. Road traffic accident forms the most common mode of injury. So efforts should be made to bring road traffic regulations into strict action and traffic norms regulated. Well established trauma care centres should be established at every Tertiary hospital. Measures for early transport of the patients from the accident site to the trauma centres should be undertaken. Clinical presentation is varied, sometimes confusing. Blunt injury abdomen is usually less obvious. Hence, repeated examination by multispecialty personnel in a specialized trauma centre is required. Erect abdomen $\mathrm{X}$ ray is a useful investigation to identify associated hollow viscus injury. With the advent of high resolution ultrasonography (FAST), DPL and FQA investigations are becoming less opted. Early diagnosis and repeated clinical examination and use of appropriate investigations forms the key in managing blunt injury of abdomen (BIA).

\section{Bibliography}

1. Sabiston ' s Text book of surgery : 18th Hedition: vol 1:2004:p483531

2. Hamilton bailey' s Emergency surgery': 13th edition 2000:p446-471

3. Surgery of the liver and biliary trackt: LH Blumgart: vol 1:3rd edition: 2000:12771318p.

4. Mohammadi A and Ghasemi M. Evaluation of gastrointestinal injury in blunt abdominal trauma "FAST is not reliable": the role of repeated ultrasonography. World Journal of Emergency Surgery. 2012, 7(2): 7922.
5. Mohammadi A, Daghighi MH, Poorisa M et al. Diagnostic Accuracy of Ultrasonography in Blunt Abdominal Trauma. Iran J Radiol. 2008, 5(3):135-139.

6. Lee BC, Ormsby EL, McGahan JP et al. The utility of sonography for the triage of blunt abdominal trauma patients to exploratory laparotomy. AJR Am J Roentgenol. 2007, 188(2): 415-21.

7. Diagnosis and management of blunt small bowel injury: a survey of membership of the American Association for the surgery of Trauma . 2000 Mar: 48(3):402-7

8. Raza M, Abbas Y, DeviV. Non operative management of abdominal trauma a 10 years review. World Journal of Emergency Surgery 2013, 8:14 doi:10.1186/17497922-8-14.

9. Giannopoulos GA, Katsoulis IE, Tzanakis NE. Non-operative management of blunt abdominal trauma. Is it safe and feasible in a district general hospital? Scandinavian Journal of Trauma, Resuscitation and Emergency Medicine 2009, 17:22 doi:10.1186/1757-7241-17-22.

10. Malhotra AK, Ivatury RR, Latifi R. Blunt abdominal trauma: evaluation and indication for laparotomy. Scandinavian Journal of Surgery. 91: 52-57, 2002.

11. Eddy H carrillo, Christopher Wohtmann, J. David Richardson, Hiram C.Polk; Evolution in the treatment of complex blunt liver injuries; current problems in surgery . Mosby; vol 38No 1, january 200, p1-60

12. Factors affecting the outcome lof patients with splenic trauma. am Surg. 2002 Mar:68 (3):232]-239.

13. Blunt trauma to spleen: Aust NZJ Surg 2000 May:70(5):333-337

14. Velmahos GC; konstantionos $1 \mathrm{G}$, et al. Nonoperative Treatment of Blunt Injury to Solid Abdominal Organs. Arch Surg 2003; 138:844-851. 
15. Schwab CW. Selection of nonoperative management candidates. World J Surg 2001;25:1389-1392.

16. Stawicki SP. Trends in nonoperative management of traumatic injury: A synopsis. OPUS 12 Scientist 2007; Vol. 1, No. 1 